\title{
ЕВРОПЕЙСКИЙ СОЮЗ В ПОСКАХ ГЛОБАЛЬНОЙ РОЛИ В УПРАВЛЕНИИ КРИЗИСАМИ (НА ПРИМЕРЕ ВЕНЕСУЭЛЫ)
}

Аннотация. Обострение кризисной ситуации в Венесуэле вновь сделало актуальным проблему эффективности международного посредничества в урегулировании сложнейших внутренних конфликтов в ключевых регионах мира. В статье анализируется стратегия Европейского союза (EC) по управлению кризисом в этой стране на примере его инициативы по созданию международной контактной группь по Венесуэле.

Ключевые слова: Международная контактная группа по Венесуэле, кризисная дипломатия, глобальная и региональная стабильность, управление кризисной ситуачией, оптимальная модель управления кризисной ситуаций.

\section{Эволюция кризиса в Венесуэле и задачи международного сообщества по его мирному разрешению}

Усугубление политического кризиса в Венесуэле, который всё больше раскачивает ситуацию в стране и может серьёзно подорвать стабильность всего региона, активизировало усилия международного сообщества по нахождению выхода из сложившегося конфронтационного тупика.

Во многом тон поиску оптимальной модели урегулирования кризисной ситуации в этой стратегически важной латиноамериканской стране задала российская дипломатия. В Москве обосновано полагают, что ключ к урегулированию конфронтации в Венесуэле лежит во всестороннем задействовании там возможностей мирного политического процесса, отказе от любых планов вооружённого вмешательства и создании общенациональной платформы для диалога между противоборствующими политическими силами с целью нахождения взаимоприемлемого компромисса.

«Только венесуэльцы имеют право определять своё будущее. Деструктивное внешнее вмешательство недопустимо. Задача международного сообщества - способствовать нахождению взаимопонимания между различными политическими силами в Венесуэле, ставящими во главу угла национальные интересы. Россия готова сотрудничать в этом направлении со всеми государствами, разделяющими данные цели», - говорилось в недавнем Заявлении МИД России в связи с событиями в Венесуэле ${ }^{1}$.

Следует отметить, что обозначенные Россией пути урегулирования ситуации полностью вытекают из принципиальных установок Устава ООН на приоритетность мирного урегулирования конфликтов и содействие созданию условий для политического диалога между конфликтующими сторонами.

Венесуэльский кризис в силу своих негативных последствий как для региональной, так

(С Щербак Игорь Николаевич - кандидат исторических наук, ведущий научный сотрудник Отдела европейской безопасности ИЕ РАН; ведущий научный сотрудник ИМИ МГИМО МИД России. Адрес: 125009 Россия, Москва, ул. Моховая, д. 11, стр. 3. E-mail: inshcherbak@gmail.com.

DOI: http://dx.doi.org/10.15211/vestnikieran320198288

1 Заявление МИД России в связи с событиями в Венесуэле от 24 января 2019 г. Официальный сайт МИД России. 
и международной стабильности, а также мировой экономики (Венесуэла - стратегически важная страна-производитель нефти) находится в фокусе внимания «кризисной дипломатии ЕС».

\section{Венесуэльский кризис в глобальном измерении антикризисной дипломатии ЕС}

Можно предположить, что решение Европейского союза о посредничестве в урегулировании венесуэльского кризиса имеет прямую связь с его амбициозными устремлениями усилить свою роль как важного игрока в глобальном управлении кризисами. И здесь есть определённая логика в подходах ЕС. Ведь Лиссабонский договор по сути дела обозначил приоритетность глобальной повестки в антикризисной стратегии Евросоюза, указав в ст. 43 на то, что в интересах управления кризисами в мире союз может использовать различные военные и гражданские инструменты, в том числе такие как «...миссии по оказанию военной помощи, миссии по поддержанию мира, операции по оказанию гуманитарной помощи и постконфликтной стабилизации, а также миссии по предотвращению конфликтов...». Учреждение ЕС международной контактной группы по Венесуэле вписывается в обозначенную стратегию и свидетельствует о расширении географической сферы антикризисной дипломатии Брюсселя. Если раньше она ограничивалась рамками соседних с Евросоюзом регионов (Ближний и Средний Восток, Африка), то теперь охватывает всё новые и новые регионы, в том числе ЮгоВосточную Азию и Латинскую Америку.

В контексте глобальных усилий антикризисной дипломатии Европейского союза интересным представляется опыт учреждения в 2005 г. совместной мониторинговой миссии ЕС и АСЕАН в Индонезии за выполнением обязательств правительства Индонезии и сепаратистского движения «Свободный Ачех», вытекающих из подписанного трёхстороннего «Меморандума о взаимопонимании» (участники - Правительство Индонезии, движение «Свободный Ачех» и «Инициатива кризисного управления» - ЕС). В меморандуме речь шла о положении провинции Ачех в составе Индонезии, участии ачехцев в политическом процессе, обеспечении прав человека, реинтеграции в общество и вопросах обеспечения безопасности, а также контроле за выполнением сторонами своих обязательств.

По мнению ряда экспертов, индонезийский опыт посредничества Евросоюза показал, что союз становится всё более востребованным как глобальный игрок в различных кризисных регионах и может стать альтернативой кризисному управлению со стороны ООН особенно в условиях, когда Совет Безопасности ООН не может в силу принципиальных разногласий между его постоянными членами принять решение о конкретных действиях по урегулированию той или иной «горячей кризисной ситуации» (в случае с Индонезией последняя не хотела интернационализации внутреннего конфликта с участием СБ ООН и предпочла сделать ставку на ЕC, который смог оперативно направить мониторинговую миссию с участием стран АCEАН и разработать концепцию политического процесса). В пользу Европейского союза работают к тому же такие факторы как сочетание возможностей «жёсткой и мягкой сил» - от операций по принуждению к миру до миссий по наблюдению за выборами - высокая степень адаптации инструментов кризисного регулирования к местным условиям, более оперативный и предсказуемый процесс принятия решений, значительные финансовые ресурсы и совокупный экономический потенциал, позволяющий интегрировать политический процесс с постконфликтным восстановлением в пострадавших странах ${ }^{1}$.

На первоначальном этапе развития кризисной ситуации ЕС, исходя из общей линии на приоритетность решения кризисных проблем путём политических переговоров, сделал став-

\footnotetext{
${ }^{1}$ Hamonic A. Les relations entre l'Union europeenne and l'ONU dans le domaine de gestion des crises. Edition Bruylant, Belgium, 2018. P. 513-616.
}

Научно-аналитический вестник ИЕ РАН, 2019, №3 
ку на создание коалиций с «единомышленниками» в поисках оптимальных методов управления кризисной ситуацией в Венесуэле. В рамках этой линии Евросоюз приветствовал создание Группы друзей Венесуэлы (Бразилия, Чили, Мексика, Португалия, Испания, США), которая была учреждена под эгидой Генерального секретаря Организации американских государств 15 января 2019 г. В заявлении подчёркивалось, что ЕС рассматривает эту группу в качестве «важного и ценного инструмента в усилиях Генерального секретаря ОАГ по созданию условий для подлинного диалога и примирения в стране» ${ }^{1}$.

Можно предположить, что выдвижению ЕС «автономной» инициативы по венесуэльскому кризису мешало отсутствие согласованной блоковой позиции всех 28 государств - членов союза по вопросу о признании лидера оппозиции Хуано Гуайдо в качестве «временного президента Венесуэлы». На заседании совета министров иностранных дел Европейского союза в Бухаресте в конце января 2019 г. Италия, а также Греция, Словакия, Мальта и Кипр по сути дела воспрепятствовали достижению полноценного консенсуса по данной проблеме.

Дальнейшее нарастание кризисной ситуации подтолкнуло ЕС к официальному выдвижению собственной инициативы - созданию при ведущей роли Евросоюза международной контактной группы по Венесуэле (соответствующее решение было принято Советом ЕС 31 января 2019 г.). Как представляется, столь беспрецедентный шаг ЕС может объяснятся следующими соображениями.

Во-первых, пониманием всей серьёзности негативных последствий кризиса в Венесуэле для региональной и глобальной стабильности (втягивание Латинской Америки в воронку дестабилизации в случае развития непредсказуемого и неуправляемого сценария в дополнение к уже имеющимся очагам региональной турбулентности на Ближнем Востоке и в Африке).

Во-вторых, возросшими стратегическими амбициями ЕС, стремящимся продемонстрировать способность влиять на глобальные и региональные процессы, в том числе в контексте предотвращения и управления кризисными ситуациями.

В-третьих, нежеланием Брюсселя оставлять «управление» кризисом в руках Вашингтона, всё больше склонного к принятию спонтанных и несогласованных с Евросоюзом решений по важным внешнеполитическим вопросам (срыв ядерной сделки с Ираном, выход из РСМД, проблема Голанских высот и т.д.)

В качестве цели группы декларировалось намерение «содействовать единообразному пониманию и скоординированному подходу ключевых международных игроков к ситуации в Венесуэле в целях мирного и демократического решения текущего кризиса». Мандат группы предусматривал решение следующих задач:

- установить связь с заинтересованными национальными игроками для понимания их подходов и требований относительно обеспечения необходимых условий для проведения свободных и справедливых выборов;

- определить устраивающие всех национальных игроков конкретные шаги и меры доверия для серьёзного участия в процессе (освобождение политзаключенных, ликвидация препятствий для равноправного участия оппозиционных партий и их лидеров в выборах, содействие оказанию внешней гуманитарной помощи нуждающемуся населению и т.д.) $)^{2}$.

Предусматривалось, что участие в работе группы со статусом наблюдателя будет открыто для всех стран, имеющих влияние на политические субъекты в Венесуэле. Группе отводи-

\footnotetext{
${ }^{1}$ Declaration of the Presidency, on behalf of the European Union on the establishment of the Group of Friends of Venezuela, P/03/9, Brussels, 21.01.2019. URL: https://press- release_PESC-03-9_en.pdf.

${ }^{2}$ International Contact Group on Venezuela. Terms of Reference, Council of the European Union. Brussels, 31.01. 2019. Colac12 CFSP/PESC 79.
}

Научно-аналитический вестник ИЕ РАН, 2019, №3 
лось всего 90 дней на реализацию её мандата и поставленных перед ней целей. Продолжение работы группы будет зависеть от развития ситуации в стране и достигнутых результатов по урегулированию кризиса. Очевидно, что такая формула даёт возможность Евросоюзу в случае дальнейшего обострения кризиса выйти из процесса без ущерба для репутации ЕС как «антикризисного менеджера».

\section{Проблемы и перспективы посредничества ЕС в урегулировании кризиса в Венесуэле}

Первое заседание контактной группы состоялось в Монтевидео 7 февраля 2019 г. при участии Германии, Боливии, Франции, Эквадора, Италии, Испании, Нидерландов, Португалии, Великобритании, Швеции. В центре внимания находились вопросы определения наиболее оптимальных путей содействия политическим силам Венесуэлы в подготовке президентских выборов в соответствии с конституцией и повышения уровня координации со стороны международного сообщества при оказании срочной гуманитарной помощи населению (в заседании участвовал спецпредставитель объединённой гуманитарной миссии Верховного Комиссара ООН по делам беженцев и Международной Организации по миграции Э. Штейн). Группе, несмотря на особую позицию Боливии, удалось достичь договорённость о том, что сопредседатели (высокий представитель ЕС по иностранным делам и политике безопасности Ф. Могерини и министр иностранных дел Уругвая Р. Новоа) установят контакты с заинтересованными лицами в Венесуэле и международными и региональными партнёрами в целях обеспечения необходимых гарантий для успешного проведения выборов, а также для срочной доставки гуманитарной помощи в соответствии с международными гуманитарными принципами. Предусматривалось, что группа направит техническую миссию в Венесуэлу для реализации этих договорённостей и проведёт следующее заседание контактной группы в первой половине марта 2019 г. в Эквадоре.

Второе заседание контактной группы на министерском уровне, состоявшееся в конце марта 2019 г. в Кито, не принесло каких-либо прорывных результатов по урегулированию кризисной ситуации. В основном были подтверждены ключевые тезисы и рекомендации первого заседания - мирное восстановление демократических и конституционных норм, проведение демократических выборов, неприятие силового решения кризиса и т.д. Поддержаны рекомендации рабочей группы по выборам о проведении электорального процесса на основе дорожной карты, согласованной всеми заинтересованными сторонами. Группа высказалась за продолжение контактов со всеми заинтересованными политическими силами как на техническом, так и на политическом уровнях. Соответствующая декларация по итогам заседания была подписана также тремя латиноамериканскими странами - Коста-Рикой, Эквадором и Уругваем. Следующее заседание группы намечено на май 2019 г. в Коста-Рике ${ }^{1}$

Руководство Европейского союза убеждено, что контактная группа способна найти ключ к урегулированию острейшего кризиса. В этой связи высокий представитель ЕС по иностранным делам Ф. Могерини, персонально курирующая деятельность группы, в своих интервью постоянно делает упор на том, что эта инициатива ЕС уникальна по своему значению, являясь единственным политическим инструментом на нынешнем этапе, имеющим доступ как к различным контрагентам внутри Венесуэлы, так и к международному сообществу. Подчёркивается также, что растёт влияние группы среди стран региона, что может открыть перспективу к переходу группы к посредничеству в урегулировании кризиса в координации с ведущими международными организациями и странами (первоначально мандат группы не преду-

\footnotetext{
1 International Contact Group on Venezuela: Ministerial Declaration, European External Action Service, Quito, 28.04.2019. URL: www.eeas.europa.eu.
}

Научно-аналитический вестник ИЕ РАН, 2019, №3 
сматривал посреднические функции).

В стратегическом плане ЕС сделал ставку на комплексный подход к управлению кризисом в Венесуэле, призванный усилить эффект своего посредничества, - сочетание политических усилий и массированной гуманитарной помощи. За последнее время Евросоюз мобилизовал 95 млн долл. на цели гуманитарной помощи как для населения Венесуэлы, так и для соседних стран, затронутых миграцией из этой страны. Особое внимание при этом уделяется, согласно заявлениям Ф. Могерини, обеспечению «политически нейтрального характера помощи ЕС на основе международных принципов и тесной координации с соответствующими международными организациями» (вопросы сотрудничества с ООН по доставке и распределению помощи обсуждались в рамках переговоров Ф. Могерини с заместителем Генерального секретаря ООН М. Лоукок) ${ }^{1}$.

К настоящему моменту у ЕС и международной контактной группы в силу сложности кризиса нет какого-либо чёткого видения его преодоления кроме общей установки на содействие «мирному, политическому и демократическому решению кризисной ситуации, исключая применение силы». Перспективы посредничества осложняются тем, что в Венесуэле продолжается «горячая фаза» кризиса - ни официальные власти, ни оппозиция пока не готовы к какому-либо компромиссу. На 1 мая 2019 г. оппозиция наметила новый раунд противостояния с Каракасом.

Эскалация политической борьбы в стране значительно сужает возможности Европейского союза влиять на процесс политического урегулирования и практически сводит на нет реализацию планов ЕС создать общенациональную платформу в Венесуэле для диалога между противоборствующими политическими силами. Отсутствие сдвигов в международном посредничестве ЕС связано с тем, что его успешная реализация невозможна без опоры на национальные платформы диалога между противоборствующими политическими силами в самой Венесуэле. И пока они не созданы вряд, ли можно надеяться на действенность международного посредничества.

Вместе с тем определённые наработки в этом плане имеются у некоторых западноевропейских экспертных сообществ, в той или иной степени связанных партнёрскими отношениями с кризисными механизмами ЕС. Например, «международная кризисная группа» (Internati-onal Crisis Group) полагает, что «оптимальным выходом было бы скорейшее возобновление переговоров между властями Венесуэлы и оппозицией, а также разрядка напряжённости меж-ду двумя де-факто президентами с последующим формированием до президентских выборов временного коалиционного правительства, состоящего из оппозиции и чавистов». Группа так-же рекомендует ЕС создать широкую коалицию государств, обеспокоенных региональной де-стабилизацией, в целях мирного и устойчивого урегулирования кризиса. И в этом плане она считает, что «успех международной контактной группы по Венесуэле будет зависеть от вклю-чения в неё не только США и стран лимской группы, но также государств, оказывающих под-держку президенту Н. Мадуро - России, Китая, Турции и Боливии». И хотя эксперты группы поддерживают в принципе введённые ЕС санкции в отношении окружения Н. Мадуро, они тем не менее призывают избегать жёстких санкций (типа введения нефтяного эмбарго), кото-рые могут ещё более усугубить бедственное экономическое положение страны. Одновре́мен-но предлагается постепенно отменять санкции по мере прогресса в мирном урегулировании ${ }^{2}$.

\footnotetext{
${ }^{1}$ Remarks by High Representative, Vice - President Federica Mogherini at the press conference following the first inaugural meeting of the International Contact Group on Venezuela, Montevideo. 07.02.2019. URL: eeas.europa.eu.

${ }_{2}$ Venezuela- a rough road ahead, International Crisis Group. 29.01.2019. P. 12. URL: https://www.opendemocracy. Научно-аналитический вестник ИЕ РАН, 2019, №3
} 


\section{Выводы}

Инициатива Евросоюза по подключению международной контактной группы по Венесуэле к урегулированию является продолжением стратегической линии ЕС на глобальную роль в управлении кризисами.

Контактная группа могла бы внести определённый вклад в ре-шение тяжелейшего внутриполитического кризиса в стране с учётом того, что ЕС дистанцировался от жёсткой линии США, допускающих вариант вооружённого вмешательства. Однако успешной реализации миссии контактной группы в плоскости достижения политического урегулирования препятствует ряд факторов. В первую очередь речь идёт о том, что противоречивый курс Брюсселя, сочетающий стремление внести вклад в урегулирование кризиса и одновре́менно признание X. Гуайдо в качестве «временного президента» (со стороны части стран Евросоюза - Германии, Франции, Нидерландов, Румынии и т.д.) вкупе с санкционным давлением на нынешние власти, не создаёт должный уровень доверия в глазах Каракаса к кон-тактной группе как к потенциальному партнёру для запуска внутриполитического диалога ${ }^{1}$.

Посреднические усилия ЕС и контактной группы могли бы быть более эффективны, если бы с самого начала ЕС взял курс на создание широкой коалиции всех государств, заинтересованных в скорейшем мирном урегулировании венесуэльского кризиса, включая Россию, КНР и др. Модификация позиции Европейского союза по режиму санкций в отношении властей Венесуэлы и признании «второго президента» придало бы дополнительную гибкость деятельности международной контактной группы как по достижению внутриполитического консенсуса так и мобилизации международной поддержки мирного процесса.

Результативность инициативы ЕС будет зависеть также от способности соперничающих политических сил в Венесуэле создать национальную платформу для диалога и обсуждения путей урегулирования нынешнего кризиса. Венесуэльский кризис показал, что всё более актуальным в контексте предотвращения внутриполитических конфликтов становится вопрос об оказании содействия странам, находящимся в зоне потенциального кризиса, в создании методологии и механизмов по предотвращению кризисных ситуаций, которые могут быть задействованы в чрезвычайных ситуациях. Такое содействие могло бы быть осуществлено не только ООН, но и по линии Европейского союза и ОБСЕ.

\section{Список литературы/References}

Declaration of the Presidency on behalf of the European Union, on the establishment of the Group of Friends of Venezuela, P/03/9, Brussels, 21.01.2019. URL: https:॥ press- release_PESC-039_en.pdf.

International Contact Group on Venezuela. Terms of Reference, Council of the European Union, Brussels, 31.01.2019, Colac12 CFSP/PESC 79.

Hamonic A. Les relations entre l'Union europternne and l'ONU dans le domaine de gestion des crises. Edition Bruylant, Belgium, 2018. P. 513-616.

International Contact Group on Venezuela: Ministerial Declaration, European External Action Service, Quito, 28.04.2019. URL: www.eeas.europa.eu.

Remarks by High Representative /Vice - President Federica Mogherini at the press conference

net/en/democraciaabierta/venezuela-rough-road-ahead/

${ }^{1}$ Venezuela: EU's inconsistency could complicate efforts to end crisis, 09.03.2019. URL: www. dw.com.

Научно-аналитический вестник ИЕ РАН, 2019, №3 
following the first inaugural meeting of the International Contact Group on Venezuela, Montevideo, 07.02.2019. URL: eeas.europa.eu.

International Contact Group on Venezuela, Terms of Reference, Council of the European Union, Brussels, 31.01.2019. Colac12 CFSP/PESC 79.

Venezuela: EU's inconsistency could complicate efforts to end crisis, 09.03.2019. URL: www. dw.com.

\section{The EU in search of a global role in the crisis management (the case of Venezuela)}

Author. Igor Shcherbak, Candidate of Sciences (History), Leading Research Associate of the Department of European Security, Institute of Europe, Russian Academy of Sciences; Leading Research Associate, IMI MGIMO. Address: 11-3, Mokhovaya str., Moscow, Russia, 1215009. Email: inshcherbak@gmail.com.

Abstract. The acute crisis in Venezuela accentuated again the problem of effectiveness of international mediation in solving complex internal conflicts in key regions of the world. The paper analyses the strategy of the European Union on the management of the crisis through the establishment of the international contact group on Venezuela.

Keywords: international contact group on Venezuela, crisis diplomacy, global and regional stability, crisis management, optimal model of crisis management.

DOI: http://dx.doi.org/10.15211/vestnikieran320198288 